\title{
Risk factors for caries incidence in a cohort of Flemish preschool children
}

\section{Roos Leroy, Kris Bogaerts, Luc Martens \& Dominique Declerck}

Clinical Oral Investigations

ISSN 1432-6981

Clin Oral Invest

DOI 10.1007/s00784-011-0579$\mathrm{y}$

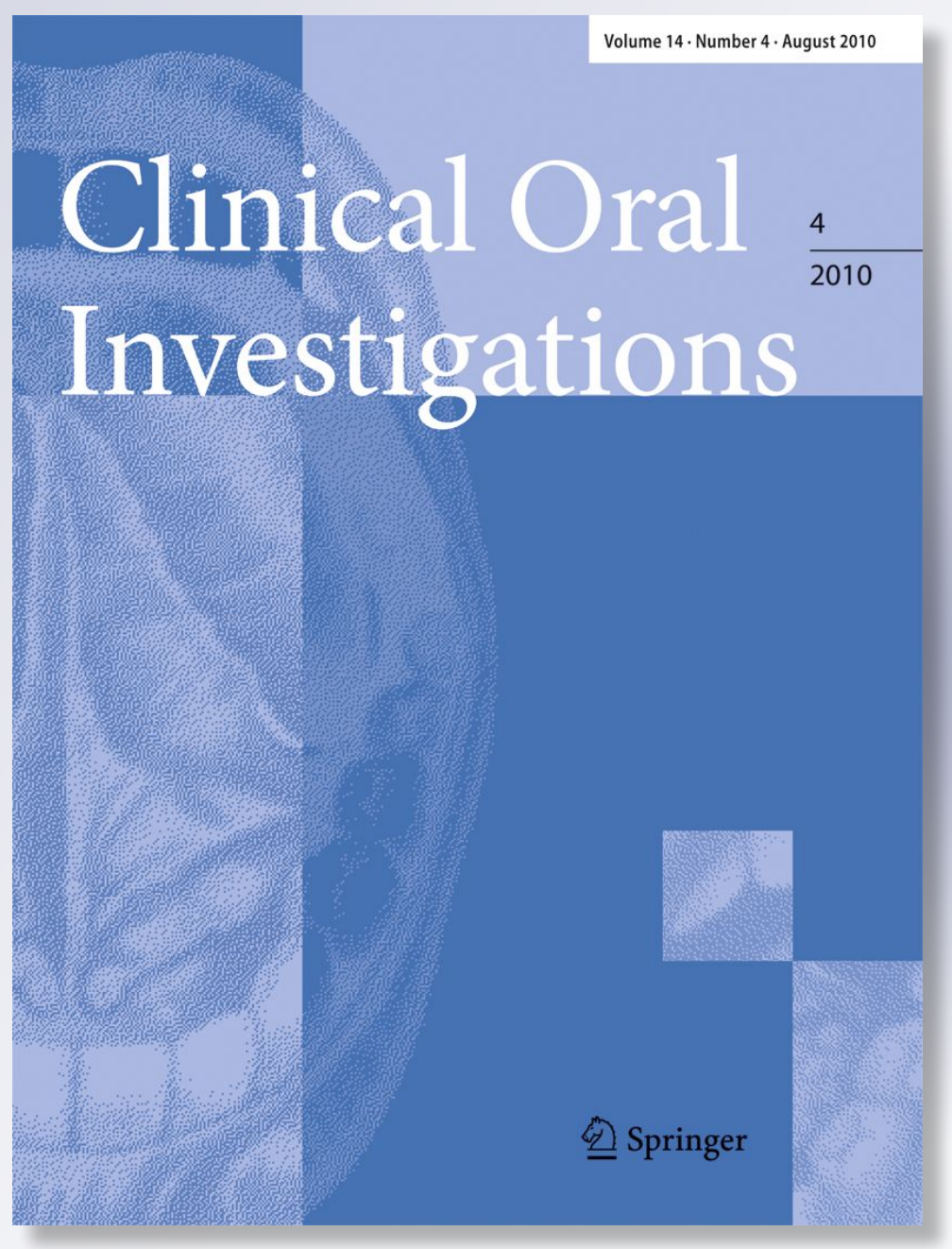

算 Springer 
Your article is protected by copyright and all rights are held exclusively by SpringerVerlag. This e-offprint is for personal use only and shall not be self-archived in electronic repositories. If you wish to self-archive your work, please use the accepted author's version for posting to your own website or your institution's repository. You may further deposit the accepted author's version on a funder's repository at a funder's request, provided it is not made publicly available until 12 months after publication. 


\title{
Risk factors for caries incidence in a cohort of Flemish preschool children
}

\author{
Roos Leroy • Kris Bogaerts • Luc Martens • \\ Dominique Declerck
}

Received: 11 February 2011 / Accepted: 6 June 2011

(C) Springer-Verlag 2011

\begin{abstract}
The main objective of this study was to identify the risk factors for the incidence of visible caries experience in a cohort of preschool children living in Flanders. Data were collected from 1,057 children; validated questionnaires on oral health-related behaviour were completed by parents at birth (2003-2004), at age 3 (2007) and 5 years (2009). At ages 3 and 5, the children were examined by trained dentists. Logistic regression analyses were performed with the following as outcome variables: visible caries experience at age 3 and increment in visible caries experience between ages 3 and 5. At ages 3 and 5, enamel and/or dentinal caries experience was observed in $22 \%$ and $41 \%$ of the cohort, respectively. The multivariable logistic regression analyses revealed that the presence of visible plaque accumulation on at least one primary tooth was a significant risk factor for visible caries experience at age 3 and for an increment in caries experience between ages 3 and 5. Children with previous caries experience at age 3
\end{abstract}

\author{
R. Leroy $\cdot$ D. Declerck \\ Paediatric Dentistry \& Special Dental Care, Katholieke \\ Universiteit Leuven, \\ Leuven, Belgium \\ K. Bogaerts \\ I-Biostat, Katholieke Universiteit Leuven and Universiteit Hasselt, \\ Leuven, Belgium

\section{Martens} \\ Paediatric Dentistry \& Special Care, PaeCaMed Research, \\ University Ghent, \\ Ghent, Belgium

\section{R. Leroy $(\bowtie)$} \\ Dental School, Katholieke Universiteit Leuven, \\ Kapucijnenvoer 7 blok a bus 7001 , \\ 3000 Leuven, Belgium \\ e-mail: Roos.leroy@med.kuleuven.be
}

had significantly higher odds for new caries lesions at age 5. Presence of visible plaque and previous caries experience are confirmed as significant risk factors for visible caries experience in preschool children. Interventions aimed at caries prevention should focus on very young children and on the control of plaque accumulation. The presence of visible plaque accumulation as a screening tool to identify young children at risk for future caries experience shows high potential.

Keywords Caries experience $\cdot$ Caries incidence $\cdot$ Oral health $\cdot$ Preschool children $\cdot$ Risk factors $\cdot$ Dental plaque

\section{Introduction}

The prevalence (and incidence) of dental caries in preschool children can be very high, as was illustrated in several studies [1-5]. According to a recent review on dental caries experience in young children, prevalence data for 5-yearolds varied between $29 \%$ in Denmark, $39 \%$ in Norway, $40 \%$ in England and Wales, $43 \%$ in Greece and $55 \%$ in Scotland [6]. These data illustrate that still a considerable proportion of young children suffer from dental caries and its consequences. Hence, prospective studies are needed which will not only yield caries incidence data but will also give a better insight into the complex multifactorial aetiology of dental caries because in prospective studies risk factors can be identified.

In 2004, Harris et al. published a systematic review on risk factors and indicators that could be significantly associated with the prevalence or incidence of dental caries in the deciduous teeth of children up to the age of 6 [7]. They identified a total of 106 factors, which could be grouped into demographic factors (e.g. parental education, 
birth order), dietary factors (e.g. frequent exposure to sugarcontaining snacks and drinks, nighttime meals and drinks), factors related to breast and/or bottle feeding (e.g. duration of bottle feeding, frequency of breast feeding), factors related to oral hygiene habits (e.g. brushing frequency, accumulation of visible plaque), factors related to oral bacteria flora (e.g. presence of Streptococci mutans, presence of Lactobacilli) and "other factors" (e.g. parental oral health behaviour, age at first dental examination). The authors confirm that longitudinal studies are essential in order to identify risk factors, as by definition, a risk factor must clearly establish that the exposure has occurred before the outcome, or before the conditions are established that make the outcome likely.

In Belgium, data on the oral health of preschool children are scarce since, among other reasons, there is no systematic collection of oral health data. According to the most recent publication, visible caries experience (at the $\mathrm{d}_{3}$ level) was observed in $7 \%$ of 3 -year-olds and $31 \%$ of 5 year-olds, randomly selected in 2003 in four geographical areas in Flanders (northern part of Belgium) [8]. So far, no prospective studies on caries incidence in preschool children have been performed in Flanders. In the present study, the following research question was addressed: What are the risk factors for visible caries experience at age 3 and for an increment in caries experience between the examinations at ages 3 and 5 ?

\section{Material and methods}

\section{Cohort}

The cohort presented here consisted of 1,057 children, selected shortly after birth in two regions in Flanders, TieltWinge and Berlaar. These children served as controls in the 'Smile for Life-Tandje de Voorste' project, an oral health promotion programme that was implemented in 2003 in two regions in Flanders (Waregem and Tielt) within the frame of the well-baby clinics organised by Kind \& Gezin ("Child \& Family"). The well-baby clinics offer preventive health care and educational guidance to parents of young children from birth until the age of 2.5 years. Although attendance of the well-baby clinics is not compulsory, the participation level in 2003 and 2004 (the years of recruitment for the study) was $97 \%$ for the home visits and ranged between $84 \%$ and $86 \%$ for attendance at consultation offices.

As in each region about 1,000 children had been born in 2002 and the preceding years, it was decided to recruit for the present study during a period of 6 months in order to obtain a cohort of at least 500 consecutively born children in each region. From the start of the study (October 2003) onwards, the nurses of Child \& Family kept track of all newborn children in the four above-mentioned regions. During the first home visit, the parents were orally and in writing informed about the project and invited to participate, to sign an informed consent and to complete a questionnaire. A baby was not adopted in the cohort if parental language skills were insufficient to complete the questionnaire, if the child had one of the predefined congenital and/or acquired general health problems which might have an oral impact (e.g. Down's syndrome, congenital cleft in lip and/or palate), if the parents did not attend the well-baby clinics or if they moved out of the region shortly after birth. In addition, in case of twins, only one child (the one whose name was alphabetically ranked first) was adopted in the study cohort.

It was scheduled to examine the children's oral health and to ask parents for information regarding oral health behaviour through questionnaires at the ages of 3 and 5 years. For this purpose, kindergartens were the most appropriate setting. In Flanders, children can attend kindergarten from 2.5 years on. Although compulsory education in Belgium only starts at the age of 6 (first year of primary school), over $99 \%$ of 3 -year-olds and $98 \%$ of 5 year-olds living in Flanders attended kindergarten in the school year 2002-2003 (source: Ministry of the Flemish Community, Education Department). Hence, in order to retrieve as many toddlers as possible at ages 3 and 5, parents were asked during the last consultations at the wellbaby clinic which kindergarten their child would attend.

\section{Questionnaires}

Parents completed questionnaires which yielded data on sociodemographic variables, children's and parental oral health behaviours at birth (2003-2004) and when the child was 3 (2007) and 5 (2009). The questionnaires were accompanied by a letter explaining the purpose of the study; at ages 3 and 5, the letter included a request for permission to have the child examined by a dentist. Questionnaires were tested and validated during a pilot study executed in another region. The inquired variables that were used in the logistic regression analyses are summarized in Table 1.

The socioeconomic status of the child was evaluated based on the reported educational level of the mother and father; these data were collected at birth. Distinction was made between parents who did not continue educational training after primary and/or secondary school ("Primary or secondary school") and parents who received higher education at the level of college, non-university or university ("Higher education or University").

If one of the parents or other caretakers of the child smoked on a regular basis in a place where the child was raised, the family smoking status was recorded as "yes"; if they quit smoking or reported that they had never smoked, the child was assigned to the "no" category. The question 
Table 1 Results of univariable regression analyses for visible caries experience at age 3 and for an increment in caries experience between the examinations at ages 3 and 5, yielding unadjusted odds ratios (OR) and 95\% confidence intervals (CI)

\begin{tabular}{|c|c|c|c|c|c|c|}
\hline \multirow[t]{2}{*}{ Variables } & \multicolumn{2}{|c|}{ At age $3(N=624)$} & \multicolumn{2}{|c|}{$\begin{array}{l}\text { At age } 5 \text { with } d_{1} m f t=0 \\
\text { at age } 3(N=404)\end{array}$} & \multicolumn{2}{|c|}{$\begin{array}{l}\text { At age } 5 \text { with } d_{1} m f t>0 \\
\text { at age } 3(N=117)\end{array}$} \\
\hline & OR & $95 \% \mathrm{CI}$ & OR & $95 \% \mathrm{CI}$ & OR & $95 \% \mathrm{CI}$ \\
\hline \multicolumn{7}{|l|}{ Sociodemographic variables } \\
\hline Region (Berlaar vs. Tielt-Winge) & 1.25 & $0.85-1.82$ & 1.20 & $0.79-1.81$ & 1.03 & $0.48-2.23$ \\
\hline Gender (boys vs. girls) ${ }^{a}$ & 1.05 & $0.72-1.53$ & 1.03 & $0.68-1.57$ & 0.61 & $0.28-1.32$ \\
\hline $\mathrm{Age}^{\mathrm{a}}$ & 3.47 & $1.31-9.16$ & 1.95 & $0.70-5.40$ & 0.80 & $0.10-6.48$ \\
\hline Ranking of the child (1st vs. 2 nd and following) ${ }^{a}$ & 1.48 & $1.01-2.18$ & 0.92 & $0.61-1.40$ & 0.87 & $0.40-1.92$ \\
\hline $\begin{array}{l}\text { Pregnancy duration in weeks ( } \leq 37 \text { weeks } \\
\text { vs. }>37 \text { weeks) }\end{array}$ & 0.99 & $0.58-1.67$ & 1.22 & $0.70-2.13$ & 0.96 & $0.33-2.77$ \\
\hline $\begin{array}{l}\text { Family situation at ages } 3 \text { and } 5 \text { (both } \\
\text { parents vs. other) }\end{array}$ & 0.87 & $0.40-1.91$ & 1.17 & $0.55-2.46$ & 0.29 & $0.03-2.41$ \\
\hline $\begin{array}{l}\text { Watching television at ages } 3 \text { and } 5 \\
(\leq 1 \mathrm{~h} / \text { day vs. }>1 \mathrm{~h} / \text { day })^{\mathrm{a}}\end{array}$ & 1.34 & $0.90-1.99$ & 1.89 & $1.23-2.91$ & 0.81 & $0.36-1.84$ \\
\hline Family smoking status at birth (no vs. yes) $^{\mathrm{a}}$ & 1.65 & $1.04-2.62$ & 0.94 & $0.54-1.65$ & 1.12 & $0.43-2.90$ \\
\hline Family smoking status at ages 3 and 5 (no vs. yes) ${ }^{\mathrm{a}}$ & 0.99 & $0.58-1.69$ & 1.20 & $0.70-2.04$ & 1.56 & $0.47-5.20$ \\
\hline \multicolumn{7}{|l|}{ Parental information } \\
\hline Parental age at birth & 1.01 & $0.96-1.05$ & 0.97 & $0.93-1.03$ & 0.99 & $0.89-1.09$ \\
\hline Educational level of mother ${ }^{\mathrm{a}}$ (low vs. high) & 1.08 & $0.73-1.59$ & 1.10 & $0.71-1.69$ & 2.37 & $1.02-5.52$ \\
\hline Educational level of father (low vs. high) & 1.15 & $0.79-1.68$ & 0.92 & $0.60-1.39$ & 2.23 & $1.01-4.91$ \\
\hline Parental dental visit at birth ( $\leq 1$ year vs. $>1$ year) & 0.66 & $0.42-1.03$ & 0.67 & $0.41-1.10$ & 1.27 & $0.56-2.91$ \\
\hline Parental dental visit at ages 3 and 5 ( $\leq 1$ year vs. $>1$ year) & 1.04 & $0.64-1.70$ & 1.35 & $0.77-2.37$ & 0.93 & $0.31-2.78$ \\
\hline Parental brushing frequency at birth $(\geq 2 \times / \text { day vs. }<2 \times / \text { day })^{\mathrm{a}}$ & 1.67 & $1.10-2.55$ & 1.19 & $0.73-1.92$ & 1.91 & $0.83-4.39$ \\
\hline $\begin{array}{l}\text { Parental brushing frequency at ages } 3 \text { and } 5(\geq 2 \times / \text { day } \\
\text { vs. }<2 \times / \text { day })^{\mathrm{a}}\end{array}$ & 1.41 & $0.94-2.11$ & 1.38 & $0.89-2.16$ & 1.19 & $0.52-2.73$ \\
\hline Interdental cleaning aids at birth (yes vs. no) ${ }^{\mathrm{a}}$ & 1.03 & $0.69-1.56$ & 1.00 & $0.64-1.57$ & 0.89 & $0.38-2.07$ \\
\hline Interdental cleaning aids at ages 3 and 5 (yes vs. no) ${ }^{\mathrm{a}}$ & 0.94 & $0.61-1.46$ & 1.88 & $1.13-3.13$ & 0.68 & $0.28-1.65$ \\
\hline \multicolumn{7}{|l|}{ Children's oral hygiene habits } \\
\hline Age at start tooth brushing ( $\leq 1$ year vs. $>1$ year) & 1.03 & $0.68-1.55$ & 1.29 & $0.81-2.06$ & 1.25 & $0.55-2.85$ \\
\hline Help with brushing at age 3 (daily vs. $<1 /$ day) ${ }^{\text {a }}$ & 1.25 & $0.81-1.92$ & 2.31 & $1.46-3.67$ & 1.49 & $0.63-3.54$ \\
\hline Help with brushing at age 5 (daily vs. $<1 /$ day) ${ }^{a}$ & NA & NA & 1.06 & $0.69-1.63$ & 1.06 & $0.47-2.35$ \\
\hline Brushing frequency at age 3 (daily vs. $<1 /$ day) & 1.27 & $0.70-2.32$ & 1.35 & $0.66-2.73$ & 1.84 & $0.46-7.38$ \\
\hline Brushing frequency at age (daily vs. $<1 /$ day) & NA & NA & 1.28 & $0.46-3.54$ & 4.52 & $0.55-37.51$ \\
\hline Plaque accumulation at ages 3 and 5 (no vs. yes) ${ }^{\mathrm{a}}$ & 2.11 & 1.44-3.09 & 1.86 & $1.21-2.87$ & 3.18 & $1.44-7.03$ \\
\hline \multicolumn{7}{|l|}{ Children's dietary habits } \\
\hline Baby feeding at birth (baby formula vs. breastfeeding) ${ }^{\mathrm{a}}$ & 1.19 & $0.79-1.78$ & 1.16 & $0.74-1.81$ & 2.75 & $1.14-6.62$ \\
\hline Baby feeding at birth (combination vs. breastfeeding) ${ }^{a}$ & 0.87 & $0.46-1.64$ & 0.83 & $0.41-1.67$ & 0.96 & $0.29-3.16$ \\
\hline Sugar-containing products on pacifier at birth (yes vs. no) & 1.39 & $0.67-2.89$ & 1.55 & $0.62-3.84$ & 3.90 & $0.46-32.84$ \\
\hline Pacifier cleaned in parents' mouth (yes vs. no) & 1.15 & $0.75-1.77$ & 1.10 & $0.70-1.75$ & 0.90 & $0.39-2.06$ \\
\hline Fluoride supplements at birth (yes vs. no) & 1.02 & $0.52-1.99$ & 0.73 & $0.37-1.47$ & 1.10 & $0.31-3.97$ \\
\hline Nursing bottle at ages 3 and 5 (yes vs. no) & 1.43 & $0.93-2.21$ & 1.11 & $0.48-2.56$ & 0.85 & $0.12-5.95$ \\
\hline Pacifier at ages 3 and 5 (yes vs. no) & 1.25 & $0.83-1.89$ & 0.46 & $0.17-1.26$ & 1.45 & $0.20-10.65$ \\
\hline $\begin{array}{l}\text { In between meals sugar-containing snacks } \\
\text { at ages } 3 \text { and } 5(<1 / \text { day vs. } \geq 1 / \text { day })^{\mathrm{a}}\end{array}$ & 1.07 & $0.66-1.71$ & 1.23 & $0.68-2.24$ & 0.49 & $0.11-2.19$ \\
\hline $\begin{array}{l}\text { In between meals sugar-containing drinks } \\
\text { at ages } 3 \text { and } 5(<1 / \text { day vs. } \geq 1 / \text { day })^{\mathrm{a}}\end{array}$ & 1.22 & $0.80-1.85$ & 1.42 & $0.91-2.20$ & 1.01 & $0.44-2.31$ \\
\hline Drinks at night at ages 3 and $5(<1 / \text { day vs. } \geq 1 / \text { day })^{\text {a }}$ & 1.51 & $0.69-3.28$ & 1.13 & $0.35-3.60$ & 0.75 & $0.12-4.84$ \\
\hline Snacks at night at ages 3 and $5(<1 / \text { day vs. } \geq 1 / \text { day })^{\text {a }}$ & 1.24 & $0.62-2.49$ & 1.12 & $0.57-2.22$ & 1.65 & $0.47-5.85$ \\
\hline Fruit juice consumption at age $5(<1 / \text { day vs. } \geq 1 / \text { day })^{a}$ & NA & NA & 1.06 & $0.68-1.65$ & 1.28 & $0.56-2.90$ \\
\hline Soda consumption at age $5(<1 / \text { day vs. } \geq 1 / \text { day })^{\text {a }}$ & NA & NA & 1.15 & $0.70-1.89$ & 1.05 & $0.43-2.56$ \\
\hline
\end{tabular}

Significant results are presented in bold. Results are derived from a multiple imputation analysis with five imputations

OR odds ratio, CI confidence interval, NA not appropriate, low educational level primary and secondary school, high educational level college or university

${ }^{\text {a }}$ Variables that were adopted in the multivariable logistic models 
on exposure to environmental smoke was adopted in the questionnaire at all three occasions (birth, age 3 and 5).

\section{Clinical examination}

The oral health examinations were carried out at age 3 and 5 years in the kindergarten of the participating children, with the children sitting on an ordinary chair. Parents were not informed about the exact date of the oral examination in order to prevent extra brushing.

Teeth were examined using a mirror with a built-in light source (Mirrorlite ${ }^{\mathrm{TM}}$ by Defend ${ }^{\circledR}$ from Medident, Belgium), and a WHO/CPITN type-E screening probe was available for the examiners in case they wanted to clean debris from a pit or fissure or they wanted to confirm the absence of a cavity. If felt necessary, teeth were cleaned and/or dried with cotton rolls before caries experience was recorded. Caries experience was scored according to the guidelines published by the British Association for the Study of Community Dentistry [9]. Caries experience was expressed using the dmft index (decayed, missing due to caries and filled teeth) [10]; for each child, a $\mathrm{dmft}$ score (sum of decayed, filled or missing due to caries deciduous teeth) was calculated. As was suggested by the participants of the Bethesda workshop on early childhood caries, both non-cavitated $\left(\mathrm{d}_{1}\right)$ and cavitated caries lesions (dcomponent of WHO index) were recorded [11]. Dental caries lesions at the $d_{1}$ level were scored according to the criteria described by Fyffe et al. [12].Theoretically, teeth should be dried before caries experience is recorded at the $d_{1}$ level. Unfortunately, the field conditions (i.e. a classroom in kindergarten) made it impossible to comply with this instruction. No radiographs were taken as the screenings were not part of routine oral health examinations. The absence/presence of dental plaque was assessed on the buccal surfaces of teeth 52, 55, 72 and 75 in accordance with Carvalho et al. [13].

Examinations were performed by six (2007) and five (2009) trained dentist examiners; all examiners participating in 2009 had been involved in 2007. Before each examination period, all examiners received a specific training for this purpose and participated in a calibration session during which in 200721 3 -year-olds and in 200932 5-year-olds were examined. Afterwards, the examiners received individual feedback. The sensitivity and specificity in the scoring of caries experience were estimated for each examiner versus the benchmark scorer (last author) since recent publications recommended the use of sensitivity and specificity scores rather than kappa scores for reporting inter-examiner reproducibility in the presence of a gold standard [14]. At the $d_{1}$ level, sensitivity scores (at mouth level) ranged between 0.67 and 1.0 in 2007 and between 0.67 and 1.00 in 2009, and specificity scores ranged between 0.50 and 0.92 in 2007 and between 0.70 and 1.00 in 2009. At the $d_{3}$ level, sensitivity scores (at mouth level) ranged between 0.67 and 0.89 in 2007 and between 0.73 and 0.91 in 2009 , specificity scores ranged between 0.83 and 1.00 in 2007 and between 0.95 and 1.00 in 2009.

\section{Ethical approval}

The study protocol received ethical approval from the Medical Ethics Committee of the Katholieke Universiteit Leuven, Belgium.

\section{Statistical methodology}

First univariable logistic regression analyses were performed with the following outcome variables: (1) visible caries experience at $d_{1}$ level at age 3 and (2) an increment in visible caries experience at $d_{1}$ level between the examinations at ages 3 and 5. Children's and parental characteristics reported at birth and ages 3 and 5 were used as explanatory variables; an overview of all evaluated variables is presented in Table 1 .

In order to account for the missing explanatory variables, multiple imputations using five imputations were performed [15]. All characteristics and outcome variables were simultaneously used in the imputation model. The imputations were done in $\mathrm{R}$ version 2.11 .1 by the aregImpute function (adaptive regression and multiple imputation) of the package Hmisc [16, 17].

In the next step, multivariable models were constructed, which allow an efficient way to control for several variables simultaneously. In order to select the variables for the multivariable logistic regression, an automatic backward selection strategy was applied to 1,000 bootstrap samples for each of the five imputed datasets. Following Heymans et al., several strategies were applied as a sensitivity analysis [18]. A $p$ value to stay of $0.5,0.175$ and 0.05 with a selection level in the 5,000 samples of $90 \%, 80 \%$ and $70 \%$ was used, respectively. Variables that were selected in all three analyses were chosen to be included in the final multivariable logistic regression model. This strategy takes into account the uncertainty created by the missing data and the sample design. Pairwise interactions between the selected variables were investigated. The proportion of variance of the dependent variable explained by the selected covariates was expressed by the adjusted sum of squares measure $\left(R^{2}\right)$ averaged over the five imputed data sets [19]. All statistical analyses were performed using SAS software version 9.2 [20].

\section{Results}

Cohort

Although it was scheduled to recruit children during 6 months, it took eventually 8 months in one region and 
10 months in the other to collect respectively 547 and 510 children whose parents consented to participate. During that time span, 768 and 886 babies had been born in these regions. In the two regions, only 15 and 25 parents fulfilling the inclusion criteria refused collaboration in the study; the major reasons were lack of interest and lack of time.

A flow chart indicating the number of children who entered the study and their follow-up (retrieval, clinical examination) over the 5 -year study period is presented in Fig. 1. Sixty-six percent $(n=701)$ of the 1,057 originally selected children were retrieved at age 3 years and $73 \%(n=$ 772 ) at age 5. The main reason for missing data at followup was failure to identify the kindergarten the child attended $(n=439)$; more details on the reasons for dropout are summarized in Table 2. Oral examinations were performed in 624 3-year-olds (59\%); 521 of them were also present at the oral examination when they were 5 .

\section{Responders versus nonresponders}

In order to evaluate potential bias due to missing data, questionnaire data obtained at baseline (i.e. birth of the child) were compared for responders (i.e. clinical examination performed at age 3 c.q. 5) and nonresponders (i.e. no clinical examination at age 3 c.q. 5). Significantly more parentsresponders reported a higher paternal educational level (i.e. higher education or university; $p=0.030$ at age 3 and $p=0.004$ at age 5) and the use of interdental cleaning aids (e.g. dental floss, proximal brushes; $p=0.003$ at age 3 and $p<0.001$ at age 5 ), while significantly more parents-nonresponders reported the current use of a nursing bottle by their child ( $p=0.023$ at age 3 and $p=0.015$ at age 5 ). In addition, significantly more children who were examined at age 5 had mothers with a higher educational level compared to their peers who were not retrieved for clinical examination $(p=0.018)$.

\section{Caries experience}

At age 3, enamel and/or dentinal caries experience (i.e. $\left.\mathrm{d}_{1} \mathrm{mft}>0\right)$ was observed in $139(22 \%)$ children; at age 5 , in $213(41 \%)$ children. Caries experience at the $d_{3}$ level (i.e. $\left.\mathrm{d}_{3} \mathrm{mft}>0\right)$ was observed in $31(5 \%)$ children examined at age 3 and in 134 (26\%) children at age 5. In $26(84 \%)$ and $73(54 \%)$ children with overt caries experience $\left(d_{3}\right)$, no restorations were observed at ages 3 and 5, respectively. In none of the 3 -year-olds and 115 -year-olds teeth had been extracted due to caries experience.

At both ages, the distribution of caries experience scores was skewed: $75 \%$ of all 335 teeth affected at the $d_{1}$ level at age 3 were observed in $70(11 \%)$ children and $76 \%$ of all 660 teeth affected at the $d_{1}$ level at age 5 were scored in $100(19 \%)$ children. In view of these very skewed dmft scores (at $d_{1}$ as well at $d_{3}$ level), it was opted not to present the means and standard deviations of the dmft scores as these are only good indicators of the central location and the spread of the data when these data are normally or at least symmetrically distributed, which was not the case.

\section{Univariable analysis}

Unadjusted odds ratios (and 95\% confidence intervals) were calculated for variables explaining (1) caries experience $\left(d_{1}\right.$ level) at age $3,(2)$ caries experience $\left(d_{1}\right.$ level $)$ at age 5 for children without visible caries experience at age 3 and (3) new caries experience $\left(\mathrm{d}_{1}\right.$ level) developed between examinations at ages 3 and 5 for children with visible caries experience at age 3 (Table 1). It was apparent that 3-yearolds who were older, not firstborn and exposed to secondhand tobacco smoke had significantly higher odds for having caries experience at the $\mathrm{d}_{1}$ level. Likewise, 5-yearolds who had not been diagnosed with visible caries experience at age 3 , who were older and who watched
Fig. 1 Number of children who entered the study and their follow-up (retrieval, clinical examination) over the 5-year study period

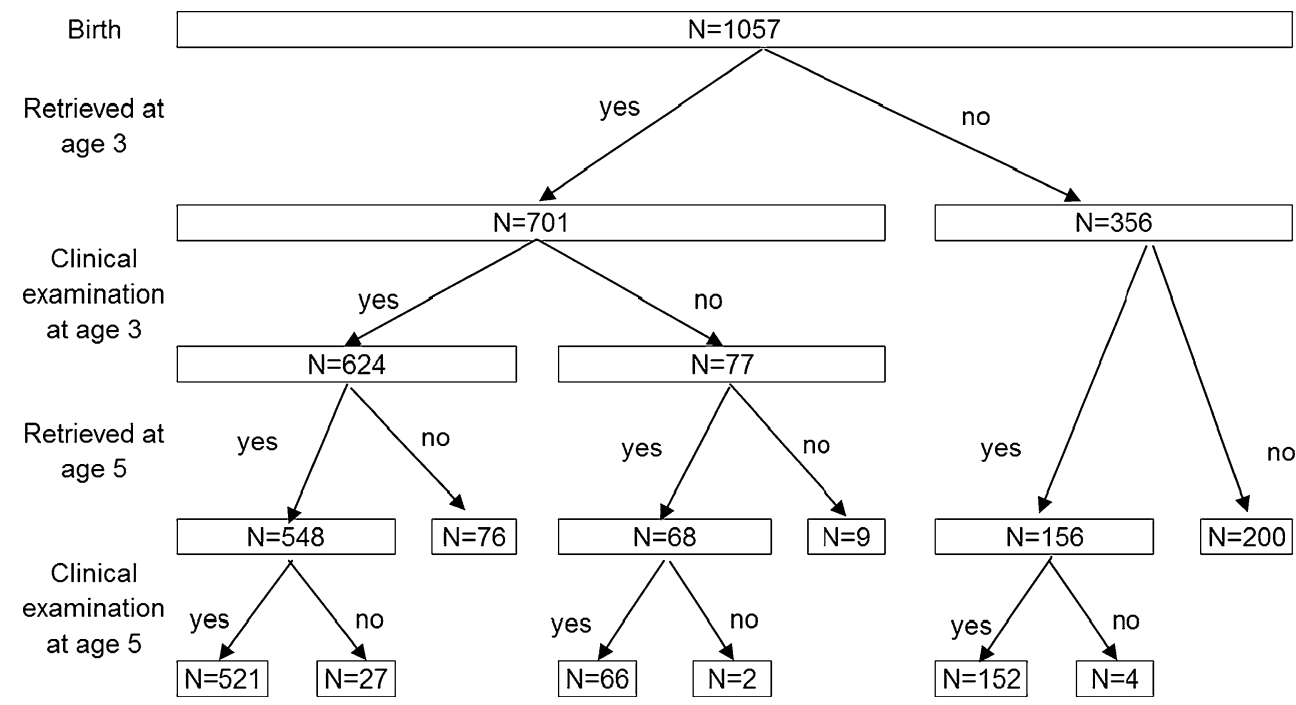


Table 2 Reasons for dropout at ages 3 and 5

\begin{tabular}{lrr}
\hline & Age 3 & Age 5 \\
\hline Child was absent on the day of examination & 31 & 28 \\
Child moved out of the study region & 28 & 7 \\
Kindergarten was not adopted in study schedule & 1 & 44 \\
Kindergarten was not known to researchers & 241 & 198 \\
Parents refused collaboration to the study & 12 & 7 \\
Kindergarten refused collaboration to the study & 43 & 1 \\
Total & 356 & 285 \\
\hline
\end{tabular}

more than $1 \mathrm{~h}$ of television a day had significant higher odds for having visible caries experience at age 5 .

Children whose parents reported at birth not brushing twice a day had significantly higher odds for presenting with visible caries experience at age 3 . Children without visible caries experience at age 3 and whose parents did not use interdental cleaning aids at regular intervals had significantly higher odds for having visible caries experience at age 5. In the peer group who had already experienced caries by age 3, a lower educational level of both mother and father was significantly associated with new visible caries experience at the $\mathrm{d}_{1}$ level at age 5 .

It was apparent that in all three groups, children who presented with dental plaque on at least one of the index teeth had significantly higher odds for having visible caries experience at the $\mathrm{d}_{1}$ level. Children whose parents reported they received help with brushing at age 3 were less likely to present with visible caries experience at age 5. No significant difference was observed between children with and without visible caries experience with respect to the age at which tooth brushing was started and the brushing frequency (as reported by the parents).

The only dietary habit that was significantly associated with an increment in caries experience between 3 and 5 was baby formula in infancy for children who had already experienced visible caries at age 3 .
Multivariable logistic regression analyses

The final multivariable logistic regression analyses revealed that 3- as well as 5-year-olds who presented with visible plaque accumulation on at least one primary tooth had two times the odds for having visible caries experience at the $d_{1}$ level compared to children who were plaque free (Table 3). In addition, children with previous caries experience (at the $\mathrm{d}_{1}$ level) at age 3 had significantly higher odds for new caries lesions at age 5 than their peers who presented without visible caries experience at age 3 . In none of the multivariable logistic regression analyses statistically significant interactions between variables were observed.

\section{Discussion}

Caries experience at the $\mathrm{d}_{1}$ and $\mathrm{d}_{3}$ levels was diagnosed in respectively $22 \%$ and $5 \%$ of 3 -year-olds and $41 \%$ and $26 \%$ of 5 -year-olds. It is tempting to conclude that these results are acceptable; yet one should realize that even lesions at the $d_{1}$ level, which indeed do not need any restorative treatment yet, are indicators that the affected child presents the risk factors for early caries experience and presumably for further caries development and hence needs appropriate preventive care.

The univariable logistic regression analyses revealed that several sociodemographic, dietary and oral hygiene habits were significantly related to the development of visible caries experience at age 3 and to the development of new caries lesions between ages 3 and 5. However, if the evaluated parameters were simultaneously adopted in multivariable models, there was only one variable that remained significant after backward selection and this in both groups considered: the presence of visible plaque accumulation. Previous reports have already indicated that the impact of visible plaque accumulation on caries development cannot be overestimated [8, 21-23]. Presumably, the presence of visible plaque accumulation can be considered a proxy for many different

Table 3 Multivariable regression analyses for visible caries experience (at $d_{1}$ level) at age 3 and for an increment in caries experience between the examinations at ages 3 and 5

\begin{tabular}{llll}
\hline Characteristic & Comparison & OR & \\
\hline Caries experience at age $3(n=624)^{\mathrm{a}}$ & & 2.11 & \\
Plaque accumulation at age 3 & Yes vs. no & & $1.44-3.09$ \\
Increment in caries experience between 3 and $5(n=521)^{\mathrm{b}}$ & & 2.79 & $1.82-4.29$ \\
Caries experience $\left(\right.$ at $\left.\mathrm{d}_{1}\right)$ at age 3 & Yes vs. no & 2.20 & $1.50-3.23$ \\
Plaque accumulation at age 5 & Yes vs. no & & \\
\hline
\end{tabular}

Results are derived from a multiple imputation analysis with five imputations

${ }^{a}$ Variables included in the analysis explained $2 \%$ of the variance

${ }^{\mathrm{b}}$ Variables included in the analysis explained $7 \%$ of the variance 
aspects: oral hygiene practices (frequency, efficiency, received help), enamel surface characteristics (roughness, texture), biofilm characteristics (microbiological composition) and dietary characteristics (sucrose content, stickiness). Further research in this field is indicated. But already now, it should be highlighted that a screening for the presence of visible plaque is a powerful tool for the detection of children at risk for caries development, and this before (irreversible) damage has taken place.

In previous reports, it was concluded that children with early caries development were at higher risk for further caries development $[24,25]$. This finding was confirmed in the present study. Hence, if the burden of caries and the high polarization of the disease are to be tackled, the efforts should be focused on very young children and their parents.

Finally, some of the limitations of the present study should be considered. Data on oral health-related habits and sociodemographic background were reported by the parents, and it was not possible to verify these data. As is well known, people, when responding to questionnaires, sometimes answer more according to a prevailing social norm than to the factual situation as they want to adhere to what is socially desirable [26]. Hence, some children may have been assigned to the wrong group. Misclassification of 'exposure' usually results in differences between groups being faded, and hence, the true risk from the exposure may be underestimated.

Since teeth were not dried, caries experience may have been underscored, and the differential diagnosis with enamel hypoplasia may have been hampered. In addition, since the dental examinations were not performed in combination with routine dental checkups or treatment appointments, no radiographic documentation was available. Exposing the children to roentgen rays only for scientific purposes was considered unethical. Consequently, it was not possible to assess hidden occlusal caries or dentin lesions on approximal surfaces, which may have led to underscoring of caries experience.

One of the major problems in prospective studies is dropout. As in the present study cohort selection was performed within the frame of well-baby clinics and followup within the frame of kindergartens, it was extremely difficult to retrieve all children as both are completely separately organised in Belgium. In addition, for reasons of privacy protection, it is in Belgium not possible to obtain the coordinates of the school a child is attending. Significantly more parents-responders reported a higher paternal or maternal educational level compared to their peers who were not retrieved. This may have had an impact on the results in this way that caries prevalence data may have been underestimated in this study since children from lower socioeconomic background were more likely to dropout.

Data presented in this report were collected in two distinct geographical areas in Flanders and as a result cannot be regarded as representative for children of that age living in Flanders. Yet, care was taken to collect within each region a cohort of at least 500 consecutively born children in order to represent the population as well as possible. But as data were obtained through questionnaires completed by the parents, one of the participation criteria for the present study was that at least one parent had sufficient language skills in Dutch, the language spoken in the northern part of Belgium. As a consequence, some immigrant children will have been excluded from the study, and hence, the sample may not truly be representative for the population of 3- and 5 -year-olds living in those regions.

In conclusion, the present study indicated that the presence of visible plaque accumulation on at least one primary tooth was a significant risk factor for visible caries experience at age 3 and for an increment in caries experience between the examinations at ages 3 and 5. Furthermore, children with caries experience at age 3 had significantly higher odds for new caries lesions at age 5 than their peers who presented without visible caries experience at age 3 . Interventions aimed at caries prevention should therefore focus on very young children and on the control of dental plaque accumulation. The presence of visible plaque accumulation as a screening tool for identifying young children at risk for future caries experience shows high potential.

Acknowledgement The following partners collaborated in the "Smile for Life Project": Dominique Declerck (Project coordinator) and Roos Leroy (both from the Department of Dentistry, Catholic University Leuven), Karel Hoppenbrouwers (Youth Health Care at the Catholic University Leuven and the Flemish Society for Youth Health Care), Emmanuel Lesaffre (I-Biostat, Katholieke Universiteit Leuven and Universiteit Hasselt, Belgium and Erasmus University Rotterdam, the Netherlands), Stephan Vanden Broucke (Research Group for Stress, Health and Well-being at the Catholic University Leuven), Luc Martens (Dental School, Ghent University) and Erwin Van Kerschaver and Martine Debyser (Child and Family). The study was supported financially by GABA Benelux and GABA International.

Conflict of interest The authors declare that they have no conflict of interest.

\section{References}

1. Douglass JM, Tinanoff N, Tang JM, Altman DS (2001) Dental caries patterns and oral health behaviors in Arizona infants and toddlers. Community Dent Oral Epidemiol 29:14-22

2. Dini EL, Holt RD, Bedi R (2000) Caries and its association with infant feeding and oral health-related behaviours in 3-4-year-old Brazilian children. Community Dent Oral Epidemiol 28:241-248

3. Mattila ML, Paunio P, Rautava P, Ojanlatva A, Sillanpaa M (1998) Changes in dental health and dental health habits from 3 to 5 years of age. J Public Health Dent 58:270-274

4. Elfrink ME, Schuller AA, Veerkamp JS, Poorterman JH, Moll HA, ten Cate BJ (2010) Factors increasing the caries risk of second primary molars in 5-year-old Dutch children. Int J Paediatr Dent $20: 151-157$ 
5. Tsai AI, Chen CY, Li LA, Hsiang CL, Hsu KH (2006) Risk indicators for early childhood caries in Taiwan. Community Dent Oral Epidemiol 34:345-437

6. Vadiakas G (2008) Case definition, aetiology and risk assessment of early childhood caries (ECC): a revisited review. Eur Arch Paediatr Dent 9:114-125

7. Harris R, Nicoll AD, Adair PM, Pine CM (2004) Risk factors for dental caries in young children: a systematic review of the literature. Community Dent Health 21(1 Suppl):71-85

8. Declerck D, Leroy R, Martens L, Lesaffre E, Garcia-Zattera MJ, Vanden Broucke S, Debyser M, Hoppenbrouwers K (2008) Factors associated with prevalence and severity of caries experience in preschool children. Community Dent Oral Epidemiol 36:168-178

9. Pine CM, Pitts NB, Nugent ZJ (1997) British Association for the Study of Community Dentistry (BASCD) guidance on the statistical aspects of training and calibration of examiners for surveys of child dental health. A BASCD coordinated dental epidemiology programme quality standard. Community Dent Health 14(Suppl 1):18-29

10. Klein H, Palmer CE (1937) Dental caries in American Indian children. Government Printing Office CP; Public Health Bulletin no. 239, Washington DC

11. Drury TF, Horowitz AM, Ismail AI, Maertens MP, Rozier RG, Selwitz RH (1999) Diagnosing and reporting early childhood caries for research purposes. A report of a workshop sponsored by the National Institute of Dental and Craniofacial Research, the Health Resources and Services Administration, and the Health Care Financing Administration. J Public Health Dent 59:192-197

12. Fyffe HE, Deery C, Nugent ZJ, Nuttall NM, Pitts NB (2000) Effect of diagnostic threshold on the validity and reliability of epidemiological caries diagnosis using the Dundee Selectable Threshold Method for caries diagnosis (DSTM). Community Dent Oral Epidemiol 28(1):42-51

13. Carvalho JC, Declerck D, Vinckier F (1998) Oral health status in Belgian 3- to 5-year-old children. Clin Oral Investig 2(1):26-30

14. Agbaje JO, Mutsvari T, Lesaffre E, Declerck D (2010) Measurement, analysis and interpretation of examiner reliability in caries experience surveys: some methodological thoughts. Clin Oral Investig. doi:10.1007/s00784-010-0475-x

15. Rubin DB (1987) Multiple imputation for nonresponse in surveys. Wiley, New York

16. R Development Core Team R (2009) A language and environment for statistical computing. R Foundation for Statistical Computing, Vienna, Austria. ISBN 3-900051-07-0, URL http://www.R-project.org. Accessed June 2010

17. Harrell FE Jr and with contributions from many other users (2009) Hmisc: Harrell Miscellaneous. R package version 3.7-0; 2009, URL http://cran.r-project.org/web/packages/Hmisc/index.html. Accessed 2 Nov 2011

18. Heymans MW, van Buuren S, Knol DL, van Mechelen W, de Vet HC (2007) Variable selection under multiple imputation using the bootstrap in a prognostic study. BMC Med Res Methodol 7:33

19. Mittlböck M, Schemper M (1999) Computing measures of explained variation for logistic regression models. Comput Methods Programs Biomed 58:17-24

20. SAS Institute Inc. (2009) SAS/STAT ${ }^{\circledR} 9.2$ user's guide, second edition. SAS Institute Inc., Cary

21. Alaluusua S, Malmivirta R (1994) Early plaque accumulation-a sign for caries risk in young children. Community Dent Oral Epidemiol 22:273-276

22. Mascarenhas AK (1998) Oral hygiene as a risk indicator of enamel and dentin caries. Community Dent Oral Epidemiol 26:331-339

23. Karjalainen S, Soderling E, Sewon L, Lapinleimu H, Simell O (2001) A prospective study on sucrose consumption, visible plaque and caries in children from 3 to 6 years of age. Community Dent Oral Epidemiol 29:136-142

24. Grindefjord M, Dahllöf G, Modéer T (1995) Caries development in children from 2.5 to 3.5 years of age: a longitudinal study. Caries Res 29:449-454

25. Litt MD, Reisine S, Tinanoff N (1995) Multidimensional causal model of dental caries development in low-income preschool children. Public Health Rep 110:607-617

26. Sjostrom O, Holst D (2002) Validity of a questionnaire survey: response patterns in different subgroups and the effect of social desirability. Acta Odontol Scand 60:136-140 